\title{
Acute treatment of stroke (except thrombectomy)
}

Paula Muñoz Venturelli MD PhD, ${ }^{1-3}$ Jason P Appleton MRCP(UK), ${ }^{4,5}$ Craig S

Anderson MD PhD, ${ }^{1,3,6}$ Philip M Bath FMedSci DSc $c^{4,5}$

1. Clinical Research Center, Instituto de Ciencias e Innovación en Medicina, Facultad de Medicina, Clínica Alemana Universidad del Desarrollo, Santiago, Chile

2. Department of Neurology and Psychiatry, Clínica Alemana de Santiago, Santiago, Chile

3. The George Institute for Global Health, University of New South Wales, Sydney, Australia

4. Stroke Trials Unit, Division of Clinical Neurosciences, University of Nottingham, Nottingham UK

5. Stroke, Nottingham University Hospitals NHS Trust, Nottingham, UK

6. The George Institute China at Peking University Health Science Center, Beijing, China

\section{Correspondence:}

Professor Craig Anderson

The George Institute for Global Health

University of New South Wales

T: +61299934521 F: +61299934502 E: canderson@georgeinstitute.org.au

Word count: 3486

References: 82 


\section{Abstract}

Purpose of Review

The management of patients with acute stroke has been revolutionized in recent years with the advent of new effective treatments. In this rapidly evolving field, we provide an update on the management of acute stroke excluding thrombectomy, looking to recent, ongoing and future trials.

\section{Recent Findings}

Large definitive trials have provided insight into acute stroke care including broadening the therapeutic window for thrombolysis, alternatives to standard dose alteplase, the use of dual antiplatelet therapy early after minor ischemic stroke, and treating elevated blood pressure in intracerebral hemorrhage. Further ongoing and future trials are eagerly awaited in this ever-expanding area.

\section{Summary}

Although definitive trials have led to improvements in acute stroke care, there remains a need for further research to improve our understanding of pathophysiological mechanisms underlying different stroke types with the potential for treatments to be tailored to the individual.

$(143 / 150$ words $)$

\section{Keywords}

Acute ischemic stroke; intracerebral hemorrhage; thrombolysis; antiplatelets; blood pressure; stroke unit. 


\section{Introduction}

Stroke is a common and devastating condition with a global incidence of 15 million people per year. ${ }^{1}$ Although one of the most exciting developments in acute ischemic stroke (AIS) in recent years is the proven effectiveness of thrombectomy in large vessel occlusion, for the remaining $85 \%$ of acute stroke patients not eligible for thrombectomy there have been several important developments. Here we provide an evidence-based update of treatments of acute stroke outwith thrombectomy, using data from recently published trials, and look to ongoing and future research for improvements in acute stroke care.

\section{Broadening the therapeutic window for use of intravenous thrombolysis in acute ischemic stroke patients with an unknown time of onset}

Reperfusion therapy with the intravenous (iv) thrombolytic agent, recombinant tissue plasminogen activator (rtPA, or alteplase), is the standard, regulatory approved, medical treatment for patients with AIS who present within 4.5 hours from symptom onset. $^{2-4}$ The safety and efficacy of this treatment is now well supported by combined data from multiple randomized controlled trials, and confirmed by clinical registry experience in real life settings. ${ }^{5}$ More recently, mechanical thrombectomy has been shown to be effective in patients meeting certain clinical characteristics and up to 24 hours from being last known to be well. ${ }^{6}$

However, making treatment decisions has been particularly challenging in the nearly 1 in 4 AIS patients who present with an unknown time of symptom onset. ${ }^{7}$ Several brain imaging modalities can help recognize potentially viable cerebral ischemia in those who present after awakening or without any history of ictus, indicating that they 
may be candidates for iv thrombolysis with an acceptable risk. ${ }^{8}$ These include (i) computed tomography (CT) perfusion, (ii) mismatch between magnetic resonance imaging (MRI) using perfusion- weighted imaging (PWI) and diffusion- weighted imaging (DWI), or (iii) the visual or semi-quantitative fluid-attenuated inversion recovery (FLAIR)-DWI mismatch on MRI. In the case of CT perfusion, diverse hemodynamic parameters, such as cerebral blood volume (CBV), cerebral blood flow (CBF), delay time (Tmax), and mean transit time (MTT), have been proposed as identifying areas of critical hypoperfusion, while the ischemic core can be defined as a region with markedly reduced $\mathrm{CBV}$ or $\mathrm{CBF}$ in combination with prolonged MTT or Tmax. However, there is no definitive consensus on which parameters and thresholds best represent critical hypoperfusion and ischemic core. ${ }^{9-11}$ While PWIDWI mismatch is the most valid method of measuring 'tissue at risk', the clear disadvantage is the longer imaging time requirement and limited availability of MRI compared to CT. In addition, there are similar difficulties with CT in determining the optimal thresholds for differentiating ischemic core from salvageable brain tissue. ${ }^{12}$ New software that provide automatic quantification of ischemic core and penumbra both with CT or MRI - have been developed to help physicians in clinical decisionmaking with faster and easier interpretation of results, and were used in recent trials to broaden thrombectomy time window. ${ }^{13}$ Finally, the presence of a visible ischemic lesion on DWI on MRI, combined with the absence of a clearly visible hyperintense signal in the same region on FLAIR - the DWI/FLAIR mismatch - shows sensitivity of $62 \%$, specificity of $78 \%$, and positive likelihood ratio of 3.6 , for detection of thrombolysis-eligible AIS patients within $4.5 \mathrm{~h}$ of stroke onset. ${ }^{8}$ This DWI/FLAIR mismatch is promising in centers with MRI availability with no need of quantification, 
to detect patients with unknown time of stroke onset who could derive benefit from iv thrombolysis.

The WAKE-UP trial (The Efficacy and Safety of MRI-Based Thrombolysis in WakeUp Stroke) aimed to determine whether alteplase would improve functional outcome in AIS patients with an unknown time of stroke onset, using DWI / FLAIR mismatch on MRI as an eligibility criteria. ${ }^{14}$ Although the trial was stopped prematurely after 503 patients were enrolled on anticipation of cessation of funding from the European Union, the study showed a significantly more favorable functional outcome at 90 days in those who received iv alteplase compared to those who received placebo. Of note, most participants had mild baseline neurological severity (median [IQR] National Institute of Health stroke scale [NIHSS] score 6 [4-9]), over two thirds had no large vessel occlusion, and those eligible for thrombectomy were excluded. In regards to safety outcomes, there were numerically more deaths and significantly more patients with type 2 parenchymal hemorrhage in the alteplase than placebo group. In summary, this trial supports the benefit of thrombolysis reperfusion treatment in patients with minor or moderate AIS who have previously been denied such treatment. Nevertheless, it may be that the higher serious adverse events seen in the alteplase group would have become significant in a larger trial.

\section{Alternatives to standard dose intravenous alteplase thrombolysis}

Standard recommended iv dose for alteplase in AIS is $0.9 \mathrm{mg} / \mathrm{kg}$, with an initial $10 \%$ of dose given as bolus over 1 minute followed by the remainder to a maximum of 90 mg over 60 minutes. $^{5}$ Lower doses of iv alteplase (most typically, $0.6 \mathrm{mg} / \mathrm{kg}$ ) have been used as an alternative to the standard regimen primarily on the basis of a perceived higher risk of intracranial hemorrhage (but also treatment affordability) in 
Asia. ${ }^{15}$ The Enhanced Control of Hypertension and Thrombolysis Stroke Study (ENCHANTED) was undertaken to directly compare low-dose with standard-dose iv alteplase but failed to clearly show non-inferiority in the primary outcome of death or disability, defined by scores of 2 to 6 on the modified Rankin scale (mRS). ${ }^{16}$ Conversely, major symptomatic intracerebral hemorrhage $(\mathrm{sICH})$ was halved, and mortality at 7 days was also lower in the low-dose group. ${ }^{16}$ A post hoc analysis suggested that patients receiving either aspirin or another antiplatelet agent prior to thrombolysis might derive benefit from the lower dose; however, no new recommendations over alteplase dose have been made in recent guidelines. ${ }^{17}$ Results from the more intensive blood pressure (BP) lowering arm of ENCHANTED are awaited, as they may provide new evidence to enhance the efficacy and safety of alteplase in AIS.

Alternatives to alteplase in AIS have been tested although neither streptokinase within 6 hours nor desmoteplase within 3 to 9 hours after symptom onset showed benefit in randomized placebo controlled trials. ${ }^{18-20}$ Tenecteplase (TNK) is the most promising alternative as it has the convenience of being administered as a single iv bolus and shows comparable efficacy and safety to iv alteplase. ${ }^{21}$ On the basis of a small number of carefully selected AIS patients with CT perfusion-identified cerebral ischemia, TNK was shown to have significantly better reperfusion and clinical outcomes than alteplase, ${ }^{22}$ while the much larger Norwegian phase III trial did not show that TNK was clearly superior (or a priori statistically non-inferior) to alteplase in 1,100 AIS subjects with predominantly mild deficits. ${ }^{23}$ Most recently, the EXTEND-IA TNK trial randomly assigned AIS patients with an occlusion of the internal carotid, basilar, or middle cerebral artery and who were eligible for thrombectomy to receive TNK (at a dose of $0.25 \mathrm{mg}$ per kilogram of body weight; maximum $25 \mathrm{mg}$ ) or 
standard dose alteplase within 4.5 hours after symptom onset. ${ }^{24}$ Reperfusion of greater than $50 \%$ of the involved ischemic territory or an absence of retrievable thrombus at the time of the initial angiographic assessment were more than double in patients treated with TNK compared to alteplase. Moreover, TNK resulted in a better 90-day functional outcome than alteplase, and without any difference in sICH between the groups. TNK is not yet an approved treatment for AIS and results of ongoing trials are awaited.

Another emerging AIS treatment strategy is use of an iv antiplatelet agent. A Cochrane review of iv glycoprotein IIb/IIla receptor antagonists for AIS found these agents to be associated with a significant risk of $\mathrm{ICH}$ without any measurable improvement in death or disability. ${ }^{25}$ However, a majority of the trial data involved the use of abciximab. ${ }^{26}$ Regarding other IV glycoprotein IIb/IIla receptor antagonists, single-arm and phase II studies of eptifibatide as adjunctive therapy to iv alteplase support ongoing trials to establish safety and efficacy, ${ }^{27,}{ }^{28}$ where the rate of $\mathrm{sICH}$ does not appear to be increased when used in in combination with standard dose alteplase. ${ }^{28}$ Results demonstrating comparable safety of this new regime with historical rates of sICH with tPA alone may prompt new trials evaluating alteplase combined with eptifibatide to improve outcomes after AIS.

\section{Improving stroke systems of care}

Well organized stroke care has demonstrated improved patient outcomes. ${ }^{29,} 30$ Having organized local stroke care protocols, established goals and quality improvement strategies, all have an important role in stroke care. ${ }^{31}$ Unfortunately, considerable regional differences remain in optimal stroke care, including access to stroke units, ${ }^{32}$ particularly in low resource settings. Such disparities require further urgent attention to reduce the burden of stroke, in particular in low and middle- 
income countries where fewer resources are available and stroke rates are increasing.

Key elements for effective stroke treatment are: (a) early symptom recognition and prompt health system access; and (b) organized system response, triage and management, once stroke is detected. In less resourced areas, early recognition, rapid transport and ready access to thrombolysis are major barriers, whereas in more mature systems, attention has shifted to bypass algorithms to offer patients the most appropriate and efficient treatment approach, reduce treatment times, and extend stroke care to facilities to where thrombolysis has been absent.

A regional system of stroke care, with operationalized bypass algorithms according to local resources, is a critical aspect comprising healthcare facilities where initial emergency care, including administration of iv alteplase can be provided; and centers capable of performing endovascular stroke treatment with comprehensive periprocedural care to which rapid transport can be arranged. Patients with a positive stroke screen (i.e. the face, arm, speech, time [FAST] algorithm) and/or a strong suspicion of stroke should be transported rapidly to the closest healthcare facility available for administration of iv alteplase, since recovery is strongly dependent on the time to treatment. ${ }^{33}$ When several iv alteplase-capable hospital options exist within a defined geographic region, the benefit of bypassing the closest to bring the patient to one that offers a higher level of stroke care is still uncertain. A number of stroke severity scales targeted at recognition of large vessel occlusion (LVO) in the prehospital setting are available, but their prediction is uncertain for recommending wider use for direct patient transfer to thrombectomy-capable centers. $^{34}$ 
Door-to-needle time (DNT) is a key performance indicator for efficient use of iv thrombolysis in AIS. Thus, quality improvement strategies have been developed to reduce treatment delays to thrombolysis. ${ }^{35}$ One of them, the Helsinki stroke model, consists of 12 interventions involving patient pre-notification, rapid clinical assessment, image acquisition, and treatment administration in a chain of responses requiring parallel processing by on-site radiology and stroke/neurology personnel. ${ }^{36}$ When applied in hospitals lacking a dedicated neurological emergency department or electronic patient records, it has led to an 18-minute reduction in in-hours DNT. ${ }^{37} \mathrm{~A}$ key success factor is the close cooperation of ambulance, emergency, and stroke teams. The transferability and impact on DNT of the Helsinki stroke thrombolysis model has been tested in hospitals with 'real-word' resources, showing a striking reduction in median in-hours DNT from 87 to $34 \mathrm{~min} .{ }^{38}$

Another barrier to appropriate stroke treatment is the lack of specialized stroke care in the emergency department, which can be critical in less resourced areas. The use of telemedicine (or telestroke) seeks to overcome this gap by providing centralized stroke care to a network of emergency departments through video consultation and examination of patients. ${ }^{39}$ Telestroke iv thrombolysis for patients with AIS has been shown to be safe and effective within a 3-hour time window, with similar rates of sICH and no difference in mortality or functional independence at 3 months when compared to iv alteplase provided at established stroke centers. ${ }^{40}$ As shown in other health problems, it is expected that the use of new technologies, such as telemedicine, will provide greater reach and improved stroke treatment in an economical manner.

\section{Antiplatelets}

The risk of recurrent vascular events after an AIS or transient ischaemic attack (TIA) 
is highest soon after the event and declines over subsequent weeks. ${ }^{41}$ Although aspirin has been shown to clearly reduce the risk of early and long-term recurrence, ${ }^{42,43}$ there has been interest in examining the efficacy and safety of shortterm use of dual antiplatelet therapy with aspirin and clopidogrel following minor stroke or high-risk TIA. The Chinese Clopidogrel in High-Risk Patients with Acute Nondisabling Cerebrovascular Events (CHANCE) trial found that combined aspirin and clopidogrel, commenced within 24 hours of onset and continued for 21 days, was superior to aspirin alone in preventing recurrent vascular events within 90 days in 5170 patients with minor AIS or TIA, with no apparent increase in hemorrhagic complications. ${ }^{44,45}$ Recently, the US-initiated Platelet-Oriented Inhibition in New TIA and minor ischaemic stroke (POINT) trial, assessed the combination of aspirin and clopidogrel versus aspirin alone for 90 days in 4881 patients within 12 hours of minor stroke or TIA. Dual antiplatelet therapy was associated with a lower risk of major ischemic events but a higher risk of major hemorrhage at 90 days and, on the advice of the trial's data safety monitoring committee, was stopped early. ${ }^{46}$

A newer antiplatelet agent, ticagrelor, licensed for use in coronary artery disease, has also been assessed against aspirin within 24 hours of minor AIS or TIA in over 13,000 patients. ${ }^{47}$ Compared with aspirin, ticagrelor was not superior at reducing the rate of combined or individual components of the endpoint of stroke, myocardial infarction or death at 90 days and was not approved for secondary stroke prevention. However, in a pre-specified exploratory analysis involving 3081 participants with ipsilateral atherosclerotic stenosis, ticagrelor was superior to aspirin at preventing the primary vascular outcome. ${ }^{48}$

As it appears that short-term dual antiplatelet therapy offers some superiority over monotherapy, a question existed as to whether triple therapy would be even better? 
The Triple Antiplatelets for Reducing Dependency after Ischaemic Stroke (TARDIS) trial assessed the combination of aspirin, clopidogrel and dipyridamole compared with guideline-recommended therapy (clopidogrel or combination aspirin and dipyridamole) commenced within 48 hours of the onset of AIS or TIA in 3096 patients. ${ }^{49}$ Triple therapy did not reduce stroke recurrence but did cause more, and more severe, bleeding than guideline antiplatelet therapy. In contrast to the previous trials, TARDIS included patients up to 48 hours after symptom onset and with more severe stroke, in whom $11 \%$ were thrombolysed.

In summary, recent trials highlight that early treatment with dual antiplatelet therapy in minor AIS or TIA is beneficial, whilst later intensive treatment increases bleeding without any additional benefits derived from reducing recurrent serious vascular events. The optimum treatment duration with dual antiplatelet therapy is unclear and further analyses to assess whether efficacy can be achieved without compromising safety are needed. Furthermore, a better understanding of underlying stroke mechanisms and etiologies may assist future research in refining approaches towards safe and efficacious treatments.

\section{Physiological management}

\section{Head positioning}

A survey of clinical practice shows considerable variation in the use of head positioning to benefit patients with acute stroke across different health care settings. ${ }^{50}$ In part, this relates to the variable uptake and residual uncertainty over the evidence indicating that the lying flat head position may benefit AIS patients from enhancing cerebral blood flow. ${ }^{51-53}$ However, a large pragmatic study that used an innovative cluster crossover design to apply lying flat versus elevated head 
positioning as a standard of care failed to show any difference in 90-day functional outcomes between the randomized groups. ${ }^{53-55}$

\section{Control of elevated blood pressure (BP)}

High BP is present in the majority of patients with acute stroke $\mathrm{e}^{56}$ and predicts increased risks of recurrent AIS, ${ }^{57}$ hematoma expansion in acute $\mathrm{ICH},{ }^{58}$ and death and dependency in both stroke types. ${ }^{59,60}$ Whether or not lowering elevated BP in acute stroke provides any benefit over the plausible risks of cerebral ischemia has been hotly debated, and despite several large trials being conducted, the evidence remains uncertain albeit with less margin. ${ }^{61}$

Two trials have focussed on acute $\mathrm{ICH}$ - the main Intensive blood pressure reduction in acute cerebral hemorrhage trial (INTERACT2, $n=2794)^{62}$ and the main Antihypertensive Treatment of Acute Cerebral Hemorrhage (ATACH-II, n=1000) $)^{63}$ and have led to changes in clinical practice. In the former, intensive BP lowering (systolic target $<140 \mathrm{mmHg}$ ) within 6 hours of symptom onset in INTERACT2 was associated with a positive shift in favorable functional outcome and improved quality of life but was neutral on primary dichotomized analysis of the mRS, compared to conventional recommended BP lowering (systolic target $<180 \mathrm{mmHg}$ ). Conversely, the latter trial showed that more intensive (achieved systolic $110-139 \mathrm{mmHg}$ ) versus 'standard' (range 140-179 mmHg, most around $140 \mathrm{mmHg}$ ) BP lowering using predominantly a single agent, nicardipine, within 4.5 hours of stroke onset was neutral. Following publication of INTERACT-2, many guidelines were updated in recommending early and intensive BP lowering to a systolic $140 \mathrm{mmHg}^{64-66}$ but publication of ATACH-II has caused some guidelines to caution intensive BP lowering in $\mathrm{ICH} .{ }^{67,68}$ However, it is important to note that INTERACT-2 and ATACHII have crucial differences in the way in which BP was managed. Firstly, the BP 
lowering effect of nicardipine in attenuating hematoma growth (and clinical outcome) may have been negated by its mild antiplatelet action. Second, systolic BP eligibility for inclusion differed between the trials (INTERACT2: 150-220 mmHg; ATACH-II $\geq 180 \mathrm{mmHg}$ ) with many ATACH-II participants receiving BP lowering prior to randomization. Third, the more aggressive approach to BP lowering in both arms of ATACH-II resulted in the guideline group having a similar on-treatment BP profile to the intensive group in INTERACT2. As such, a lower systolic target of 110-139 $\mathrm{mmHg}$ maybe too low and aggressive than the $<140 \mathrm{mmHg}$ within 1 hour used in INTERACT2. ${ }^{61}$

Current guidelines recommend lowering elevated BP to $<185 / 110 \mathrm{mmHg}$ in the setting of thrombolysis for AIS. ${ }^{66-68}$ The results of the ENCHANTED-BP trial, which is assessing whether more intensive BP lowering (systolic $<140 \mathrm{mmHg}$ ) improves outcome in patients undergoing thrombolysis are awaited in $2019 .{ }^{69}$ Several large trials have assessed BP lowering in AIS and found it to be safe and feasible but without influencing overall clinical outcome. ${ }^{70}$ Early treatment ( $<6$ hours) with transdermal glyceryl trinitrate (GTN) was associated with improved clinical outcomes in a subgroup of the Efficacy of Nitric Oxide in Stroke (ENOS) trial, ${ }^{71}$ in line with a small, single-center, ambulance-based study assessing the same medication. ${ }^{72}$ The larger (n 1000) Rapid Intervention with Glyceryl trinitrate in Hypertensive stroke Trial-2 (RIGHT-2) is assessing transdermal GTN within 4 hours of symptom onset in a relatively unselected pre-hospital stroke population. ${ }^{73}$

\section{Oxygen}

Hypoxia is common, affecting two thirds of people with acute hemiparetic stroke, ${ }^{74}$ and most often intermittent and undetected, yet associated with higher rates of poor outcomes including neurological deterioration, ${ }^{75}$ death, and death and 
institutionalisation. ${ }^{76}$ The Stroke Oxygen Study (SOS) trial assessed the effectiveness of prophylactic low-dose oxygen therapy for three days in 8003 nonhypoxic individuals with acute stroke and found no difference in 90 day death or disability between treatment groups. ${ }^{77}$ However, participants mainly had mild strokes (NIHSS score median 5) and were recruited an average of 20 hours after symptom onset. Thus, whether oxygen therapy is beneficial in the first few hours of acute stroke remains unclear. High-flow oxygen therapy is currently being tested in AIS patients with the rationale that oxygenation of ischemic and surrounding tissues may be protective in those patients with more severe strokes mediated by large vessel occlusion. ${ }^{78}$ In the meantime, oxygen supplementation should be limited to those with reduced saturations $(<95 \%)$ and without any contraindications. ${ }^{66}$

\section{Glucose}

High glucose within the first 24 hours of onset has been associated with poor outcome following both AIS and acute ICH. However, glycemic control has not been shown to improve outcome after AIS. ${ }^{79}$ Therefore, guidelines recommend a medium level range of target blood glucose levels in AIS: $7.8-10 \mathrm{mmol} / \mathrm{L}^{17}$ versus. $5-15$ $\mathrm{mmol} / \mathrm{L} .{ }^{66}$ The third in the series, INTERACT-3, is currently assessing more early and intensive glucose management as part of a bundle of care, for improving outcome in acute ICH (NCT03209258).

\section{Oedema}

In the setting of malignant middle cerebral artery infarction with associated cerebral edema, decompressive hemicraniectomy is a proven life-saving treatment in those aged $>60$ years - with a similar survival benefit to younger patients - within 48 hours of symptom onset. ${ }^{17,66}$ Therefore, prompt referral for neurosurgery in suspected cases is required for a shared decision-making approach to ensure agreement over 
the potential for surviving with residual disability. Medical therapies for cerebral oedema are commonly used in clinical practice, but have limited proven benefit. Mannitol, an intravascular osmotic agent, reduces cerebral oedema and lowers intracranial pressure but there is no trial evidence of efficacy in either AIS or ICH. ${ }^{80}$ In INTERACT-2, mannitol use was common (two thirds) but safe and without any influence on outcome in a post-hoc analysis. ${ }^{81}$ The sulfonylurea receptor 1 inhibitor glibenclamide given initiated within 10 hours and continued for 3 days after large anterior circulation AIS has been shown to improve markers of cerebral oedema, but not surprisingly, no effect on clinical outcome was shown in a small $(n=86)$ phase II trial. ${ }^{82}$ Future trials of medical therapies in cerebral oedema in both AIS and ICH are needed.

\section{Treatment failures}

\section{Neuroprotection}

Despite numerous trials of pharmacological and non-pharmacological therapies with putative neuroprotective mechanisms, none have proved efficacious in acute stroke, and are therefore not recommended. ${ }^{17}$ Whether neuroprotective therapies have a role in patients eligible for recanalization in AIS is unclear, and requires further study.

\section{Early anticoagulation}

A Cochrane review found that early anticoagulation within 14 days of AIS was not associated with any net short- or long-term benefit in 24 trials totalling 23,748 patients. ${ }^{83}$ Anticoagulation increased bleeding risk despite reducing rates of stroke recurrence, deep vein thrombosis and pulmonary embolus. Thus, the benefits of 
anticoagulation are offset by increased bleeding and are not recommended routinely early after AIS. ${ }^{17}$

\section{Conclusion}

In summary, there have been significant improvements in our understanding of, and potential ability to treat, acute stroke. Recent large trial results need to be adopted by national and international guidelines to aid implementation into clinical practice. There remains a need for further research to improve our understanding of the pathophysiological mechanisms underlying different stroke types so that, in future, treatments can be tailored to the individual stroke patient. 


\section{Key references (published in the last 3 years)}

\section{Of major importance:}

14. Thomalla G, Simonsen CZ, Boutitie F, Andersen G, Berthezene Y, Cheng B, et al. Mri-guided thrombolysis for stroke with unknown time of onset. N Engl J Med. 2018.

WAKE-UP trial: Alteplase vs. normal saline in those with stroke of unknown time of onset with MRI diffusion-FLAIR mismatch was associated with improved 90 day functional outcome.

24. Campbell BCV, Mitchell PJ, Churilov L, Yassi N, Kleinig TJ, Dowling RJ, et al. Tenecteplase versus alteplase before thrombectomy for ischemic stroke. $N$ Engl J Med. 2018;378:1573-1582

EXTEND-IA TNK trial: TNK vs. alteplase in large vessel occlusion pre-thrombectomy. TNK reduced the need for thrombectomy and improved 90 day functional outcome without increasing $\mathrm{s} \mathrm{CH}$.

46. Johnston SC, Easton JD, Farrant M, Barsan W, Conwit RA, Elm JJ, et al. Clopidogrel and aspirin in acute ischemic stroke and high-risk tia. $N$ Engl $\mathrm{J}$ Med. 2018

POINT trial: aspirin and clopidogrel vs. aspirin within 12 hours of minor stroke or TIA was associated with reduced major ischemic events but increased major bleeding at 90 days. 
63. Qureshi Al, Palesch YY, Barsan WG, Hanley DF, Hsu CY, Martin RL, et al. Intensive blood-pressure lowering in patients with acute cerebral hemorrhage. N Engl J Med. 2016;375:1033-1043

ATACH-II trial: intensive vs. standard BP lowering within 4.5hrs of ICH onset did not influence functional outcome at 90 days for reasons discussed above.

\section{Of importance:}

16. Anderson CS, Robinson T, Lindley RI, Arima H, Lavados PM, Lee TH, et al. Lowdose versus standard-dose intravenous alteplase in acute ischemic stroke. $N$ Engl $J$ Med. 2016;374:2313-2323

ENCHANTED trial: low-dose vs. standard-dose alteplase failed to show noninferiority, but those on antiplatelet agents pre-stroke may benefit from low-dose.

49. Bath PM, Woodhouse LJ, Appleton JP, Beridze M, Christensen H, Dineen RA, et al. Antiplatelet therapy with aspirin, clopidogrel, and dipyridamole versus clopidogrel alone or aspirin and dipyridamole in patients with acute cerebral ischaemia (tardis): A randomised, open-label, phase 3 superiority trial. The Lancet. 2018;391:850-859 TARDIS trial: triple antiplatelet therapy vs. guideline therapy with 24 hours of AIS or TIA did not reduce stroke recurrence but did cause more, and more severe bleeding.

54. Anderson CS, Arima H, Lavados P, Billot L, Hackett ML, Olavarría VV, et al. Cluster-randomized, crossover trial of head positioning in acute stroke. New England Journal of Medicine. 2017;376:2437-2447 
HEADPOST trial: lying flat vs. elevated head positioning in acute stroke did not influence 90 day functional outcome.

77. Roffe C, Nevatte T, Sim J, Bishop J, Ives N, Ferdinand P, et al. Effect of routine low-dose oxygen supplementation on death and disability in adults with acute stroke:

The stroke oxygen study randomized clinical trial. JAMA. 2017;318:1125-1135

SOS trial: three days of prophylactic low-dose oxygen therapy did not influence functional outcome at 90 days. 


\section{References}

1. Mackay J, Mensah G. The atlas of heart disease and stroke. Who library. 2004. Available from:

Http://www.Who.Int/cardiovascular_diseases/resources/atlas/en/.

2. Lees KR, Emberson J, Blackwell L, Bluhmki E, Davis SM, Donnan GA, et al. Effects of alteplase for acute stroke on the distribution of functional outcomes: A pooled analysis of 9 trials. Stroke. 2016;47:2373-2379

3. Hacke W, Kaste M, Bluhmki E, Brozman M, Davalos A, Guidetti D, et al. Thrombolysis with alteplase 3 to 4.5 hours after acute ischemic stroke. New England Journal of Medicine. 2008;359:1317-1329

4. Hacke W, Kaste M, Fieschi C, Toni D, Lesaffre E, von Kummer R, et al. Intravenous thrombolysis with recombinant tissue plasminogen activator for acute hemispheric stroke. The european cooperative acute stroke study (ecass). JAMA. 1995;274:1017-1025

5. Wahlgren N, Ahmed N, Davalos A, Ford GA, Grond M, Hacke W, et al. Thrombolysis with alteplase for acute ischaemic stroke in the safe implementation of thrombolysis in stroke-monitoring study (sits-most): An observational study. Lancet. 2007;369:275-282

6. Sheinberg DL, McCarthy DJ, Peterson EC, Starke RM. Defuse-3 trial: Reinforcing evidence for extended endovascular intervention time window for ischemic stroke. World Neurosurg. 2018;112:275-276

7. Fink JN, Kumar S, Horkan C, Linfante I, Selim MH, Caplan LR, et al. The stroke patient who woke up: Clinical and radiological features, including diffusion and perfusion mri. Stroke. 2002;33:988-993 
8. Thomalla G, Cheng B, Ebinger M, Hao Q, Tourdias T, Wu O, et al. Dwi-flair mismatch for the identification of patients with acute ischaemic stroke within $4.5 \mathrm{~h}$ of symptom onset (pre-flair): A multicentre observational study. Lancet Neurol. 2011;10:978-986

9. Wintermark M, Flanders AE, Velthuis B, Meuli R, van Leeuwen M, Goldsher D, et al. Perfusion-ct assessment of infarct core and penumbra: Receiver operating characteristic curve analysis in 130 patients suspected of acute hemispheric stroke. Stroke. 2006;37:979-985

10. Bivard A, Levi C, Spratt N, Parsons M. Perfusion ct in acute stroke: A comprehensive analysis of infarct and penumbra. Radiology. 2013;267:543550

11. Campbell BC, Christensen S, Levi CR, Desmond PM, Donnan GA, Davis SM, et al. Comparison of computed tomography perfusion and magnetic resonance imaging perfusion-diffusion mismatch in ischemic stroke. Stroke. 2012;43:2648-2653

12. Dani KA, Thomas RG, Chappell FM, Shuler K, MacLeod MJ, Muir KW, et al. Computed tomography and magnetic resonance perfusion imaging in ischemic stroke: Definitions and thresholds. Ann Neurol. 2011;70:384-401

13. Albers GW, Marks MP, Kemp S, Christensen S, Tsai JP, Ortega-Gutierrez S, et al. Thrombectomy for stroke at 6 to 16 hours with selection by perfusion imaging. N Engl J Med. 2018;378:708-718

14. Thomalla G, Simonsen CZ, Boutitie F, Andersen G, Berthezene Y, Cheng B, et al. Mri-guided thrombolysis for stroke with unknown time of onset. $N$ Engl J Med. 2018 
15. Kim BJ, Han MK, Park TH, Park SS, Lee KB, Lee BC, et al. Low-versus standard-dose alteplase for ischemic strokes within 4.5 hours: A comparative effectiveness and safety study. Stroke. 2015;46:2541-2548

16. Anderson CS, Robinson T, Lindley RI, Arima H, Lavados PM, Lee TH, et al. Low-dose versus standard-dose intravenous alteplase in acute ischemic stroke. N Engl J Med. 2016;374:2313-2323

17. Powers WJ, Rabinstein AA, Ackerson T, Adeoye OM, Bambakidis NC, Becker K, et al. 2018 guidelines for the early management of patients with acute ischemic stroke: A guideline for healthcare professionals from the american heart association/american stroke association. Stroke. 2018;49:e46-e110

18. Hacke W, Furlan AJ, Al-Rawi Y, Davalos A, Fiebach JB, Gruber F, et al. Intravenous desmoteplase in patients with acute ischaemic stroke selected by mri perfusion-diffusion weighted imaging or perfusion ct (dias-2): A prospective, randomised, double-blind, placebo-controlled study. Lancet Neurol. 2009;8:141-150

19. Hacke W, Albers G, Al-Rawi Y, Bogousslavsky J, Davalos A, Eliasziw M, et al. The desmoteplase in acute ischemic stroke trial (dias): A phase ii mri-based 9hour window acute stroke thrombolysis trial with intravenous desmoteplase.

Stroke. 2005;36:66-73

20. von Kummer R, Mori E, Truelsen T, Jensen JS, Gronning BA, Fiebach JB, et al. Desmoteplase 3 to 9 hours after major artery occlusion stroke: The dias-4 trial (efficacy and safety study of desmoteplase to treat acute ischemic stroke). Stroke. 2016;47:2880-2887

21. Huang X, Cheripelli BK, Lloyd SM, Kalladka D, Moreton FC, Siddiqui A, et al. Alteplase versus tenecteplase for thrombolysis after ischaemic stroke (attest): 
A phase 2, randomised, open-label, blinded endpoint study. Lancet Neurol. $2015 ; 14: 368-376$

22. Parsons M, Spratt N, Bivard A, Campbell B, Chung K, Miteff F, et al. A randomized trial of tenecteplase versus alteplase for acute ischemic stroke. $N$ Engl J Med. 2012;366:1099-1107

23. Logallo N, Novotny V, Assmus J, Kvistad CE, Alteheld L, Ronning OM, et al. Tenecteplase versus alteplase for management of acute ischaemic stroke (nor-test): A phase 3, randomised, open-label, blinded endpoint trial. Lancet Neurol. 2017;16:781-788

24. Campbell BCV, Mitchell PJ, Churilov L, Yassi N, Kleinig TJ, Dowling RJ, et al. Tenecteplase versus alteplase before thrombectomy for ischemic stroke. $N$ Engl J Med. 2018;378:1573-1582

25. Ciccone A, Motto C, Abraha I, Cozzolino F, Santilli I. Glycoprotein iib-iiia inhibitors for acute ischaemic stroke. Cochrane Database Syst Rev. 2014:CD005208

26. Abciximab Emergent Stroke Treatment Trial I. Emergency administration of abciximab for treatment of patients with acute ischemic stroke: Results of a randomized phase 2 trial. Stroke. 2005;36:880-890

27. Adeoye O, Sucharew H, Khoury J, Tomsick T, Khatri P, Palesch Y, et al. Recombinant tissue-type plasminogen activator plus eptifibatide versus recombinant tissue-type plasminogen activator alone in acute ischemic stroke: Propensity score-matched post hoc analysis. Stroke. 2015;46:461-464

28. Adeoye O, Sucharew H, Khoury J, Vagal A, Schmit PA, Ewing I, et al. Combined approach to lysis utilizing eptifibatide and recombinant tissue-type 
plasminogen activator in acute ischemic stroke-full dose regimen stroke trial. Stroke. 2015;46:2529-2533

29. Langhorne P, O'Donnell MJ, Chin SL, Zhang H, Xavier D, Avezum A, et al. Practice patterns and outcomes after stroke across countries at different economic levels (interstroke): An international observational study. The Lancet. 2018;391:2019-2027

30. Stroke Unit Trialists C. Organised inpatient (stroke unit) care for stroke. Cochrane Database Syst Rev. 2013;9:CD000197

31. Schwamm LH, Fonarow GC, Reeves MJ, Pan W, Frankel MR, Smith EE, et al. Get with the guidelines-stroke is associated with sustained improvement in care for patients hospitalized with acute stroke or transient ischemic attack. Circulation. 2009;119:107-115

32. Munoz Venturelli P, Robinson T, Lavados PM, Olavarria VV, Arima H, Billot L, et al. Regional variation in acute stroke care organisation. J Neurol Sci. $2016 ; 371: 126-130$

33. Saver JL, Fonarow GC, Smith EE, Reeves MJ, Grau-Sepulveda MV, Pan W, et al. Time to treatment with intravenous tissue plasminogen activator and outcome from acute ischemic stroke. JAMA. 2013;309:2480-2488

34. Krebs W, Sharkey-Toppen TP, Cheek F, Cortez E, Larrimore A, Keseg D, et al. Prehospital stroke assessment for large vessel occlusions: A systematic review. Prehospital emergency care : official journal of the National Association of EMS Physicians and the National Association of State EMS Directors. 2018;22:180-188

35. Fonarow GC, Smith EE, Saver JL, Reeves MJ, Hernandez AF, Peterson ED, et al. Improving door-to-needle times in acute ischemic stroke: The design and 
rationale for the american heart association/american stroke association's target: Stroke initiative. Stroke. 2011;42:2983-2989

36. Meretoja A, Strbian D, Mustanoja S, Tatlisumak T, Lindsberg PJ, Kaste M. Reducing in-hospital delay to 20 minutes in stroke thrombolysis. Neurology. 2012;79:306-313

37. Meretoja A, Weir L, Ugalde M, Yassi N, Yan B, Hand P, et al. Helsinki model cut stroke thrombolysis delays to 25 minutes in melbourne in only 4 months. Neurology. 2013;81:1071-1076

38. Wu TY, Coleman E, Wright SL, Mason DF, Reimers J, Duncan R, et al. Helsinki stroke model is transferrable with "real-world" resources and reduced stroke thrombolysis delay to $34 \mathrm{~min}$ in christchurch. Front Neurol. 2018;9:290

39. Akbik F, Hirsch JA, Chandra RV, Frei D, Patel AB, Rabinov JD, et al. Telestroke-the promise and the challenge. Part one: Growth and current practice. J Neurointerv Surg. 2017;9:357-360

40. Kepplinger J, Barlinn K, Deckert S, Scheibe M, Bodechtel U, Schmitt J. Safety and efficacy of thrombolysis in telestroke: A systematic review and metaanalysis. Neurology. 2016;87:1344-1351

41. Rothwell PM, Giles MF, Chandratheva A, Marquardt L, Geraghty O, Redgrave $\mathrm{JN}$, et al. Effect of urgent treatment of transient ischaemic attack and minor stroke on early recurrent stroke (express study): A prospective populationbased sequential comparison. Lancet. 2007;370:1432-1442

42. International Stroke Trial Collaborative Group. The international stroke trial (ist); a randomised trial of aspirin, subcutaneous heparin, both, or neither among 19435 patients with acute ischaemic stroke. Lancet. 1997;349:15691581 
43. CAST (Chinese Acute Stroke Trial) Collaborative Group. Cast: Randomised placebo-controlled trial of early aspirin use in 20,000 patients with acute ischaemic stroke. Lancet. 1997;349:1641-1649

44. Wang Y, Wang Y, Zhao X, Liu L, Wang D, Wang C, et al. Clopidogrel with aspirin in acute minor stroke or transient ischemic attack. N Engl J Med. 2013;369:11-19

45. Wong KS, Wang Y, Leng X, Mao C, Tang J, Bath PM, et al. Early dual versus mono antiplatelet therapy for acute non-cardioembolic ischemic stroke or transient ischemic attack: An updated systematic review and meta-analysis. Circulation. 2013;128:1656-1666

46. Johnston SC, Easton JD, Farrant M, Barsan W, Conwit RA, Elm JJ, et al. Clopidogrel and aspirin in acute ischemic stroke and high-risk tia. $N$ Engl J Med. 2018

47. Johnston S, Amarenco P, Alberts G, Denison H, Easton J, Evans S, et al. Ticagrelor versus aspirin in acute stroke or transient ischemic attack. $N$ Engl J Med. 2016;375:35-43

48. Amarenco P, Albers GW, Denison H, Easton JD, Evans SR, Held P, et al. Efficacy and safety of ticagrelor versus aspirin in acute stroke or transient ischaemic attack of atherosclerotic origin: A subgroup analysis of socrates, a randomised, double-blind, controlled trial. The Lancet Neurology. $2017 ; 16: 301-310$

49. Bath PM, Woodhouse LJ, Appleton JP, Beridze M, Christensen H, Dineen RA, et al. Antiplatelet therapy with aspirin, clopidogrel, and dipyridamole versus clopidogrel alone or aspirin and dipyridamole in patients with acute cerebral 
ischaemia (tardis): A randomised, open-label, phase 3 superiority trial. The Lancet. 2018;391:850-859

50. Munoz Venturelli P, Olavarria V, Gonzalez F, Brunser A, Lavados P, Arima H, et al. Head position in the early phase of acute ischemic stroke: An international survey of current practice. J Stroke Cerebrovasc Dis. 2015;24:1564-1569

51. Olavarría VV, Arima H, Anderson CS, Brunser AM, Muñoz-Venturelli P, Heritier S, et al. Head position and cerebral blood flow velocity in acute ischemic stroke: A systematic review and meta-analysis. Cerebrovascular Diseases. 2014;37:401-408

52. Brunser AM, Muñoz Venturelli P, Lavados PM, Gaete J, Martins S, Arima H, et al. Head position and cerebral blood flow in acute ischemic stroke patients: Protocol for the pilot phase, cluster randomized, head position in acute ischemic stroke trial (headpost pilot). International Journal of Stroke. 2016;11:253-259

53. Olavarría VV, Brunser A, Munoz Venturelli P, Arima H, Gonzalez F, Gaete J, et al. Head position in stroke trial (headpost) pilot phase results. European Stroke Journal. 2016;1:3-612

54. Anderson CS, Arima H, Lavados P, Billot L, Hackett ML, Olavarría VV, et al. Cluster-randomized, crossover trial of head positioning in acute stroke. New England Journal of Medicine. 2017;376:2437-2447

55. Muñoz-Venturelli $\mathrm{P}$, Arima $\mathrm{H}$, Lavados $\mathrm{P}$, Brunser A, Peng B, Cui L, et al. Head position in stroke trial (headpost) - sitting-up vs lying-flat positioning of patients with acute stroke: Study protocol for a cluster randomised controlled trial. Trials. 2015;16:256 
56. Britton M, Carlsson A, de Faire U. Blood pressure course in patients with acute stroke and matched controls. Stroke. 1986;17:861-864

57. Sprigg N, Gray LJ, Bath PMW, Boysen G, De Deyn PP, Friis P, et al. Relationship between outcome and baseline blood pressure and other haemodynamic mreasures in acute ischaemic stroke: Data from the taist trial. J Hypertension. 2006;24:1413-1417

58. Ohwaki K, Yano E, Nagashima H, Hirata M, Nakagomi T, Tamura A. Blood pressure management in acute intracerebral hemorrhage - relationship between elevated blood pressure and hematoma enlargement. Stroke. $2004 ; 35: 1364-1367$

59. Leonardi-Bee J, Bath PM, Phillips SJ, Sandercock PA. Blood pressure and clinical outcomes in the international stroke trial. Stroke. 2002;33:1315-1320

60. Willmot M, Leonardi-Bee J, Bath PM. High blood pressure in acute stroke and subsequent outcome: A systematic review. Hypertension. 2004;43:18-24

61. Bath PM, Appleton JP, Krishnan K, Sprigg N. Blood pressure in acute stroke: To treat or not to treat: That is still the question. Stroke. 2018

62. Anderson CS, Heeley E, Huang Y, Wang J, Stapf C, Delcourt C, et al. Rapid blood-pressure lowering in patients with acute intracerebral hemorrhage. $N$ Engl J Med. 2013;368:2355-2365

63. Qureshi Al, Palesch YY, Barsan WG, Hanley DF, Hsu CY, Martin RL, et al. Intensive blood-pressure lowering in patients with acute cerebral hemorrhage. N Engl J Med. 2016;375:1033-1043

64. Steiner T, Al-Shahi Salman R, Beer R, Christensen H, Cordonnier C, Csiba L, et al. European stroke organisation (eso) guidelines for the management of 
spontaneous intracerebral hemorrhage. International Journal of Stroke. 2014;9:840-855

65. Hemphill J, Greenberg S, Anderson C, Becker K, Bendok B, Cushman M, et al. Guidelines for the management of spontaneous intracerebral hemorrhage. Stroke. 2015;Early online

66. Royal College of Physicians. National clinical guideline for stroke. Prepared by the intercollegiate stroke working party. 2016

67. Whelton PK, Carey RM, Aronow WS, Casey DE, Jr., Collins KJ, Dennison Himmelfarb C, et al. 2017 acc/aha/aapa/abc/acpm/ags/apha/ash/aspc/nma/pcna guideline for the prevention, detection, evaluation, and management of high blood pressure in adults: Executive summary: A report of the american college of cardiology/american heart association task force on clinical practice guidelines. Hypertension. 2018;71:1269-1324

68. Leung AA, Daskalopoulou SS, Dasgupta K, McBrien K, Butalia S, Zarnke KB, et al. Hypertension canada's 2017 guidelines for diagnosis, risk assessment, prevention, and treatment of hypertension in adults. Can J Cardiol. 2017;33:557-576

69. Huang Y, Sharma V, Robinson T, Lindley R, Chen X, Kim J, et al. Rationale, design, and progress of the enhanced control of hypertension andthrombolysis stroke study (enchanted) trial: An international multicenter $2 \times 2$ quasi-factorial randomized controlled trial of low- vs. Standard-dose rt-pa andearly intensive vs. Guideline-recommended blood pressure lowering in patientswith acute ischaemic stroke eligible for thrombolysis treatment. International Journal of Stroke. 2015;10:778-788 
70. Bath PM, Krishnan K. Interventions for deliberately altering blood pressure in acute stroke. Cochrane Database of Systematic Reviews. 2014;(10): CD000039.pub3.doi: 10.1002/14651858.CD000039

71. Woodhouse L, Scutt P, Krishnan K, Berge E, Gommans J, Ntaios G, et al. Effect of hyperacute administration (within 6 hours) of transdermal glyceryl trinitrate, a nitric oxide donor, on outcome after stroke: Subgroup analysis of the efficacy of nitric oxide in stroke (enos) trial. Stroke. 2015;46:3194-3201

72. Ankolekar S, Fuller M, Cross I, Renton C, Cox P, Sprigg N, et al. Feasibility of an ambulance-based stroke trial, and safety of glyceryl trinitrate in ultra-acute stroke: The rapid intervention with glyceryl trinitrate in hypertensive stroke trial (right, isrctn66434824). Stroke. 2013;44:3120-3128

73. Appleton JP, Scutt P, Dixon M, Howard H, Haywood L, Havard D, et al. Ambulance-delivered transdermal glyceryl trinitrate versus sham for ultraacute stroke: Rationale, design and protocol for the rapid intervention with glyceryl trinitrate in hypertensive stroke trial-2 (right-2) trial (isrctn26986053). Int J Stroke. 2017:1747493017724627

74. Ferdinand P, Roffe C. Hypoxia after stroke: A review of experimental and clinical evidence. Exp Trans/ Stroke Med. 2016;8:9

75. Rocco A, Pasquini M, Cecconi E, Sirimarco G, Ricciardi MC, Vicenzini E, et al. Monitoring after the acute stage of stroke: A prospective study. Stroke. $2007 ; 38: 1225-1228$

76. Rowat AM, Dennis MS, Wardlaw JM. Hypoxaemia in acute stroke is frequent and worsens outcome. Cerebrovascular diseases (Basel, Switzerland). $2006 ; 21: 166-172$ 
77. Roffe C, Nevatte T, Sim J, Bishop J, Ives N, Ferdinand P, et al. Effect of routine low-dose oxygen supplementation on death and disability in adults with acute stroke: The stroke oxygen study randomized clinical trial. JAMA. $2017 ; 318: 1125-1135$

78. Stroke Alliance for Europe. Proof trial. 2018;2018

79. Gray CS, Hildreth AJ, Sandercock PA, O'Connell JE, Johnston DE, Cartlidge $\mathrm{NE}$, et al. Glucose-potassium-insulin infusions in the management of poststroke hyperglycaemia: The uk glucose insulin in stroke trial (gist-uk). Lancet Neurology. 2007;6:397-406

80. Bereczki D, Liu M, Fernandes do Prado G, Fekete I. Mannitol for acute stroke. Cochrane Database of Systematic Reviews. 2007

81. Wang X, Arima H, Yang J, Zhang SH, Wu GJ, Woodward M, et al. Mannitol and outcome in intracerebral hemorrhage propensity score and multivariable intensive blood pressure reduction in acute cerebral hemorrhage trial 2 results. Stroke. 2015;46:2762-2767

82. Sheth KN, Elm JJ, Molyneaux BJ, Hinson H, Beslow LA, Sze GK, et al. Safety and efficacy of intravenous glyburide on brain swelling after large hemispheric infarction (games-rp): A randomised, double-blind, placebo-controlled phase 2 trial. The Lancet Neurology. 2016;15:1160-1169

83. Sandercock PAG, Counsell C, Kane EJ. Anticoagulants for acute ischaemic stroke. Cochrane Database of Systematic Reviews. 2015 
Table 1: Summary of recent major acute stroke trial results

\begin{tabular}{|c|c|c|c|c|c|}
\hline & Trial & Population & Intervention & Outcome & Comment \\
\hline \multicolumn{6}{|l|}{ Thrombolysis for AIS } \\
\hline $\begin{array}{l}\text { Broadening the } \\
\text { thrombolysis time window }\end{array}$ & WAKE-UP & $\begin{array}{l}503 \text { AIS patients with } \\
\text { unknown time of } \\
\text { onset }\end{array}$ & $\begin{array}{l}\text { MRI DWI/FLAIR } \\
\text { mismatch: alteplase vs. } \\
\text { placebo }\end{array}$ & $\begin{array}{l}\text { More favorable functional } \\
\text { outcome at } 90 \text { days in } \\
\text { alteplase vs. placebo groups }\end{array}$ & $\begin{array}{l}\text { Alteplase is safe and } \\
\text { efficacious when using MRI } \\
\text { DWI/FLAIR mismatch } \\
\text { eligibility }\end{array}$ \\
\hline $\begin{array}{l}\text { Lower dose alteplase }(0.6 \\
\mathrm{mg} / \mathrm{kg})\end{array}$ & ENCHANTED & $\begin{array}{l}3310 \text { AIS patients } \\
\text { within } 4.5 \text { hours of } \\
\text { onset }\end{array}$ & $\begin{array}{l}\text { Alteplase } 0.6 \text { mg/kg vs. } \\
0.9 \mathrm{mg} / \mathrm{kg}\end{array}$ & Failed to show non-inferiority & $\begin{array}{l}\text { Post-hoc analysis: those } \\
\text { on antiplatelet agents may } \\
\text { benefit from lower dose }\end{array}$ \\
\hline \multirow[t]{2}{*}{ Tenecteplase (TNK) } & NOR-TEST & $\begin{array}{l}1100 \text { AIS patients } \\
\text { within } 4.5 \text { hours of } \\
\text { onset }\end{array}$ & $\begin{array}{l}\text { TNK } 0.4 \mathrm{mg} / \mathrm{kg} \text { vs. } \\
\text { alteplase } 0.9 \mathrm{mg} / \mathrm{kg}\end{array}$ & $\begin{array}{l}\text { No difference in functional } \\
\text { independence by day } 90\end{array}$ & $\begin{array}{l}\text { Predominantly mild strokes } \\
\text { and a high proportion of } \\
\text { mimics recruited }\end{array}$ \\
\hline & EXTEND-IA & $\begin{array}{l}202 \text { AIS within } 4.5 \mathrm{hrs} \\
\text { with large vessel } \\
\text { occlusion eligible for } \\
\text { thrombectomy }\end{array}$ & $\begin{array}{l}\text { TNK } 0.25 \mathrm{mg} / \mathrm{kg} \text { vs. } \\
\text { alteplase pre- } \\
\text { thrombectomy }\end{array}$ & $\begin{array}{l}\text { TNK resulted in increased } \\
\text { recanalization rates at } \\
\text { angiography and improved } \\
90 \text { day functional outcome }\end{array}$ & $\begin{array}{l}\text { No difference in } \\
\text { symptomatic ICH rates }\end{array}$ \\
\hline \multicolumn{6}{|l|}{ Antiplatelets } \\
\hline \multirow[t]{2}{*}{$\begin{array}{l}\text { Dual antiplatelet therapy } \\
\text { (DAPT) in minor stroke } \\
\text { and TIA }\end{array}$} & CHANCE & $\begin{array}{l}5170 \text { minor stroke or } \\
\text { TIA patients within } \\
24 \text { hours of onset }\end{array}$ & $\begin{array}{l}\text { Clopidogrel + Aspirin vs. } \\
\text { aspirin alone for } 21 \text { days }\end{array}$ & $\begin{array}{l}\text { DAPT reduced recurrent } \\
\text { vascular events without } \\
\text { increasing hemorrhage rates } \\
\text { at } 90 \text { days }\end{array}$ & Chinese population \\
\hline & POINT & $\begin{array}{l}4881 \text { minor stroke or } \\
\text { TIA patients within } \\
12 \text { hours of onset }\end{array}$ & $\begin{array}{l}\text { Clopidogrel + Aspirin vs. } \\
\text { aspirin alone for } 90 \text { days }\end{array}$ & $\begin{array}{l}\text { DAPT reduced major } \\
\text { ischemic events but } \\
\text { increased major hemorrhage } \\
\text { rates at } 90 \text { days }\end{array}$ & Trial stopped early \\
\hline Ticagrelor & SOCRATES & $\begin{array}{l}13000 \text { minor stroke } \\
\text { or TIA within } 24 \\
\text { hours of onset }\end{array}$ & Ticagrelor vs. Aspirin & $\begin{array}{l}\text { Ticagrelor not superior to } \\
\text { aspirin }\end{array}$ & $\begin{array}{l}\text { In a secondary analysis, } \\
\text { Ticagrelor was superior to } \\
\text { aspirin in those with } \\
\text { ipsilateral carotid stenosis }\end{array}$ \\
\hline
\end{tabular}




\begin{tabular}{|c|c|c|c|c|c|}
\hline $\begin{array}{l}\text { Triple antiplatelets in } \\
\text { stroke and TIA }\end{array}$ & TARDIS & $\begin{array}{l}3096 \text { stroke or TIA } \\
\text { patients within } 48 \\
\text { hours of onset }\end{array}$ & $\begin{array}{l}\text { Aspirin + Dipyridamole + } \\
\text { Clopidogrel vs. guideline } \\
\text { therapy (Aspirin }+ \\
\text { Dipyridamole or } \\
\text { Clopidogrel only) for } 28 \\
\text { days }\end{array}$ & $\begin{array}{l}\text { Triple therapy did not reduce } \\
\text { stroke recurrence but did } \\
\text { increase bleeding }\end{array}$ & $\begin{array}{l}\text { Trial stopped early due to } \\
\text { futility } \\
11 \% \text { thrombolysed }\end{array}$ \\
\hline Head positioning & HEADPOST & $\begin{array}{l}11093 \text { acute stroke } \\
\text { patients }\end{array}$ & $\begin{array}{l}\text { Lying flat vs. elevated } \\
\text { head positioning for } 24 \\
\text { hours }\end{array}$ & $\begin{array}{l}\text { No difference in 90-day } \\
\text { functional outcome }\end{array}$ & $\begin{array}{l}\text { Mild strokes } \\
\text { Position initiated an } \\
\text { average of } 14 \text { hours after } \\
\text { symptom onset }\end{array}$ \\
\hline Control of elevated BP & $\begin{array}{l}\text { INTERACT2 } \\
\text { ATACH-II }\end{array}$ & $\begin{array}{l}2794 \mathrm{ICH} \text { patients } \\
\text { within } 6 \text { hours of } \\
\text { onset } \\
1000 \mathrm{ICH} \text { patients } \\
\text { within } 4.5 \text { hours of } \\
\text { onset }\end{array}$ & $\begin{array}{l}\text { Intensive (systolic target } \\
<140 \mathrm{mmHg}) \text { vs. } \\
\text { guideline (<180 mmHg) } \\
\text { Intensive (110-139 } \\
\mathrm{mmHg}) \text { vs. 'standard' } \\
(140-179 \mathrm{mmHg})\end{array}$ & $\begin{array}{l}\text { Intensive: favorable shift in } \\
\text { functional outcome, improved } \\
\text { quality of life } \\
\text { No difference in } 90 \text {-day } \\
\text { functional outcome }\end{array}$ & $\begin{array}{l}\text { Mixture of agents used } \\
\text { Predominantly nicardipine }\end{array}$ \\
\hline Oxygen & SOS & $\begin{array}{l}8003 \text { non-hypoxic } \\
\text { acute stroke patients }\end{array}$ & $\begin{array}{l}\text { Prophylactic low-dose } \\
\text { oxygen therapy vs. none } \\
\text { for } 3 \text { days }\end{array}$ & $\begin{array}{l}\text { No difference in 90-day } \\
\text { functional outcome }\end{array}$ & $\begin{array}{l}\text { Mild strokes, recruited an } \\
\text { average of } 20 \text { hours after } \\
\text { symptom onset }\end{array}$ \\
\hline
\end{tabular}

